\title{
What should be our approach to knowledge translation in primary care?
}

\author{
Samir Gupta \\ From Knowledge transfer in primary care: the model of allergic respiratory diseases \\ Quebec City, Canada. 7 May 2010
}

Evaluations of delivered care have consistently demonstrated gaps between existing medical knowledge and current practice. Studies examining the quality of care across disciplines and jurisdictions have estimated that $30 \%$ to $45 \%$ of patients are not offered evidence-based best care, and $20 \%$ to $30 \%$ receive contraindicated and potentially harmful care $[1,2]$.

Respiratory disease care gaps are equally alarming, with only $48 \%$ of recommended care delivered to patients with asthma exacerbations, and only $46 \%$ of routine recommended care delivered to patients with COPD [3]. Knowledge translation (KT) is a methodological approach developed specifically to address these care gaps. Because the most prevalent conditions are managed predominantly in primary care, there has been a great deal of interest in developing KT interventions targeting the primary care environment. A meta-analysis of randomized trials of guideline implementation interventions has demonstrated only modest effects on care across a wide range of disciplines, care settings, recommendation types and intervention types [4].

However, few of these studies employed behavioral theories to inform intervention design, and this lack of an appropriate theoretical underpinning may be partly responsible for their limited success [5]. A multi-step approach to $\mathrm{KT}$ intervention design might improve success. Knowledge implementers should start by investigating the theory-based factors that underlie existing clinical practice, in order to identify the theoretical constructs that should be targeted by an intervention. Once these factors are known, one can design interventions to enhance the processes supporting change in these specific constructs [6].

\footnotetext{
Correspondence: Samir.gupta@mail.mcgill.ca

Department of Medicine, University of Toronto, Toronto, Ontario, M5S 1A1, Canada
}

When targeting individual behaviour change, relevant theoretical categories include motivational theories (which explain how individuals wish, intend and ultimately decide to change behaviour), action theories (which explain how individuals move from intention to actual behaviour change), and stage theories (which describe an orderly progression through discrete stages toward behaviour change) [6]. Concepts of behavioural intention and self-efficacy are among the best predictors of subsequent health behaviour and are found in virtually all social cognitive models of health behaviour. Baseline factors influencing current behaviour can be identified directly through previous literature, or through direct measurement via interviews, questionnaires or group methods. An alternative approach is to analyze practice variation with respect to its determinants. With this technique, determinants identified predominantly in practices which adhere to or do not adhere to behaviour can be characterized as facilitators or barriers, respectively. Finally, researchers can analyze previously effective KT interventions to retrospectively ascertain which factors were likely influencing behaviour [7].

After having thus identified the relevant components of a behavior that should be targeted, an appropriate intervention can be developed based on approaches previously shown to be effective in other settings. General categories of interventions include educational interventions, which can be passive or interactive; audit-and-feedback; provision of "just-in-time" information, including reminders and clinical decision support systems; organizational changes such as role revisions or financial incentives; and patient-directed interventions such as pre-consultation questionnaires. Electronic tools are emerging as a modality to facilitate a wide range of these interventions and require further study. 


\section{References}

1. Schuster MA, McGlynn EA, Brook RH: How good is the quality of health care in the United States? Milbank Q 1998, 76:517-563.

2. McGlynn EA, Asch SM, Adams J, Keesey J, Hicks J, DeCristofaro A, Kerr EA: The quality of health care delivered to adults in the United States. $N$ Engl J Med 2003, 348:2635-2645.

3. Mularski RA, Asch SM, Shrank WH, Kerr EA, Setodji CM, Adams JL, Keesey J, McGlynn EA: The quality of obstructive lung disease care for adults in the United States as measured by adherence to recommended processes. Chest 2006, 130:1844-1850.

4. Grimshaw JM, Thomas RE, MacLennan G, Fraser C, Ramsay CR, Vale L, Whitty P, Eccles MP, Matowe L, Shirran L, et al: Effectiveness and efficiency of guideline dissemination and implementation strategies. [Review] [47 refs]. Health Technology Assessment 2004, 8:1-72.

5. Davies $P$, Walker $A E$, Grimshaw JM: A systematic review of the use of theory in the design of guideline dissemination and implementation strategies and interpretation of the results of rigorous evaluations. Implement Sci 2010, 5:14.

6. Eccles M, Grimshaw J, Walker A, Johnston M, Pitts N: Changing the behavior of healthcare professionals: the use of theory in promoting the uptake of research findings. J Clin Epidemiol 2005, 58:107-112.

7. Knowledge Translation in Health Care: Moving from Evidence to Practice. London: Wiley-Blackwell;SE Straus, JM Tetroe, ID Graham 2009.

doi:10.1186/1710-1492-6-S4-A4

Cite this article as: Gupta: What should be our approach to knowledge translation in primary care? Allergy, Asthma \& Clinical Immunology 2010 6(Suppl 4):A4.

\section{Submit your next manuscript to BioMed Central and take full advantage of:}

- Convenient online submission

- Thorough peer review

- No space constraints or color figure charges

- Immediate publication on acceptance

- Inclusion in PubMed, CAS, Scopus and Google Scholar

- Research which is freely available for redistribution

Submit your manuscript at www.biomedcentral.com/submit
Biomed Central 